\title{
Reducing asymmetry in doctor-patient interaction: patients' initiatives in specialised clinical \\ encounters
}

Piera Margutti

Renata Galatolo

\section{Introduction}

The paper focuses upon patients' initiatives during specialised medical encounters in an Italian centre for prosthesis construction and application. Our main interest is to describe how patients use verbal and gestural resources to gain opportunities for conversational initiatives and the way in which these are legitimised, in order to make them acceptable in the interaction. Thus, detracting from the passive character traditionally associated to patients' communication, this study contributes to more recent works on doctor-patient interaction that, in contrast to more traditional studies in the field, have focused on patients' communicative behaviour.

Doctor-patient interaction is similar to all types of institutional interaction (Drew and Heritage, 1992) insofar as, besides being characterised by asymmetrical competence among participants, is organized in such a way that the institutional party (the doctor) is in control of the communication in order to achieve the institutional aims most effectively. As a result, participants have reduced speaking rights, as compared to interaction in ordinary settings and, consequently, the turntaking system result to be more limited; furthermore, each party is entitled to specific and specialised conversational types of actions (Drew \& Heritage, 1992, p. 26). So, for example, while carrying out their institutional tasks, doctors more often ask questions, while patients normally answer to those questions. These "specialised turn-types" -questions and answers- are systematically associated to one or the other of the parties, providing to the interaction its asymmetrical and institutional character.

Sequences of questions and answers thus distributed among participants characterise each of the phases of the visit and, especially, the phase dedicated to the gathering of information about the patient's present and past health conditions (history taking). Previous works on doctor-patient 
interaction in primary care visits (Boyd \& Heritage, 2006), have highlighted that in the history-taking phase doctors' questions are always designed to achieve other ends besides that of just getting information. So, for instance, by asking questions, doctors select and choose the relevant topics in the ongoing encounter, they communicate their assumptions on patients and their life styles and, moreover, influence patients' answers in terms of both forms and content. On the other hand, as patients are concerned, it has been demonstrated that they can adopt different types of behaviour in relation to the requirements of the questions, thus contrasting the asymmetry and gaining conversational opportunities by taking advantage of the answer space assigned to them. So, for instance, they can exploit their answering turn to introduce topics and issues which are not addressed in the doctors' questions. ${ }^{1}$

2. The role of the multimodal pattern in introducing patients' initiatives

This paper addresses a recurrent practice in our data, which consists of patients' use of a multi-modal pattern -mobilizing words, gaze and gestures- to introduce interactional initiatives that are shaped as expansions of their answering turns or, alternatively, as autonomous and independent turns. In all the occurrences, through this specific multi-modal pattern, patients refer to the amputated limb, both as the topic of their discouse and as the object of the physical examination.

The following example illustrates one such case, in which the patient expands his response turn by means of this multi-modal pattern.

(1) RGPM/P5 (3:56)

$\mathrm{P}$ has had his right hand amputated. The doctor MC is filling a form with the details of the amputation. ${ }^{2}$

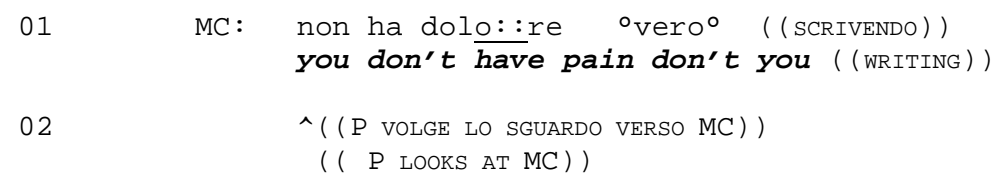

${ }^{1}$ See Ten Have (1991), Gill (1998), Robinson (2001), Gill and Maynard (2006), Stivers and Heritage (2001): all of them provide detailed analysis of patients' initiatives .

${ }^{2}$ Gestures and gaze produced by $\mathrm{P}$ and by the doctor are described in glosses in lower-case printing between round brackets. The $\operatorname{symbol}^{\wedge}$ indicates the gesture onset and the moment when the gaze addresses the recipient, in correspondence to the talk under way. 


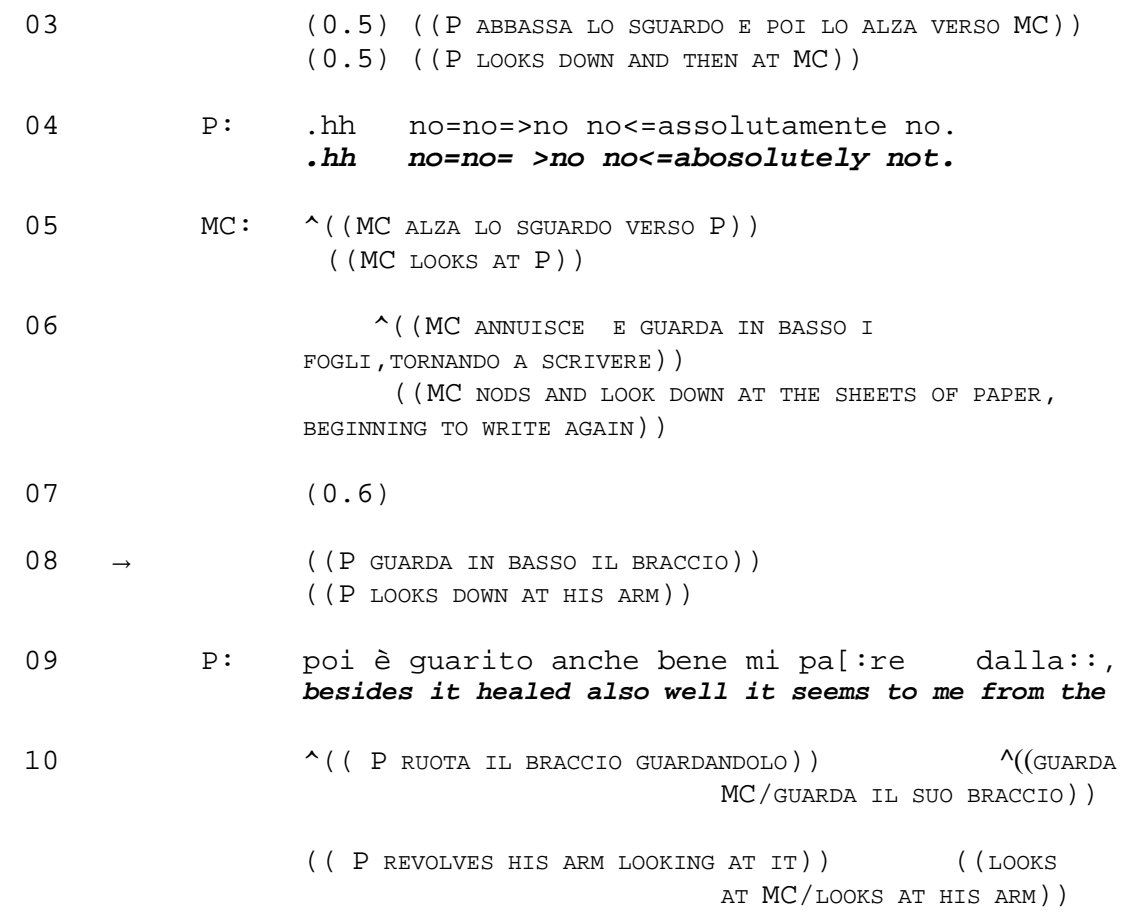

In the fragment, the interrogative utterance produced by $\mathrm{MC}$ is designed to elicit one of the two alternative options; in this case, the negative answer is the preferred one. P produces the requested answer (line 4). It is worth considering that the repetition and the adverb "absolutely" emphasise the answer's alignment to the requirement of the question. MC's nodding and the fact that he attends to filling the form (line 6) indicate that he has receipted the answer, thus closing the question-answer sequence.

The phenomenon at issue here takes place after the closure of the question-answer sequence. Starting from the line indicated by the arrow, $\mathrm{P}$ produces this specific cluster of communicative modalities, which is composed of the three following components:

- the gaze addresses the part of his/her body on which the talk has focused upon and which has been the object of the physical examination so far (line 8); 
- the production of a turn as connected to P's prior talk and, as such, designed as an expansion, to introduce a further topic (i.e. the limb's recovery, which the doctor did not ask about (line 9);

- the gesture through which P moves the amputated limb that has just been examined (in this case, the amputated arm, line 10). The gesture functions as a pointing as far as it makes explicit and visible which part or the aspect of the limb $\mathrm{P}$ is referring to (for instance, the way in which the limb has recovered or the motility of the limb itself).

The analysis describes the way in which this multimodal pattern is constructed and how patients methodically and recurrently use it in this particular setting to gain conversational spaces besides and beyond just answering. Moreover, we identify the types of actions that patients produce through this multimodal pattern, as well as the strategies whereby they make their initiative acceptable. More specifically, we show that by means of these integrated multimodal resources, patients manage to ease the tension between two contrasting needs: on one hand, the need of introducing topics they think are relevant for the decision doctors have to take about the prosthesis application and, on the other, that of mitigating these initiatives in order to make them acceptable in the context of the visit. Patients accomplish mitigation by showing that their assessments and assertions bear on objective facts that are accessible to doctors too. By displaying that they share access to the assessable with doctors -in other words, the limb is right there, accessible to doctors as well as to thempatients manage to elicit the doctors' participation to the activity they have initiated. This aspect contributes to mitigate the initiative; patients display their being oriented to acknowledge the asymmetry of the setting and the doctors' authority, although they take an autonomous and independent initiative.

\section{Data and method}

This study is based on a corpus of 10 video-recorded clinical encounters in which patients meet physicians and prosthesis technicians in a specialised centre for the construction and application of prosthesis to people who have lost their limbs because of working accidents or illness. Video-recordings have been taken during the first encounters patients have with the 
institution, in which a team of doctors and technicians examine the patient, decide which type of prosthesis is more suitable in relation to his health conditions and needs, prescribe the prosthesis and the rehabilitation programme and, under specific circumstances, sometimes also a surgical operation. $\mathrm{P}$ is often accompanied by a relative. Sometimes a nurse takes part to the meeting. All the participants are seated at a table facing each other: on one side the medical team composed of a prosthesis technician, a surgeon specialised in hand (or foot, legs, etc) surgery, a physician, and a doctor engineer; on the other side, the patient and the person accompanying him. Two cameras were used (one static and the other mobile), in order to record the interaction from both parties' point of view. Data were transcribed according to the conventions developed by Gail Jefferson (Atkinson \& Heritage, 1984). In the transcriptions we added glosses reporting the description of gaze movements and gestures. The analysis adopts the Conversation Analysis approach.

\section{Analysis}

The analysis we propose is a multimodal one. We analyse in detail the integration of gaze, talk and gestures in the patients' behaviour, with the aim of showing the way in which this pattern is enacted methodically and systematically in our data. To this purpose, we start by returning to look at the previous extract, as reported below:

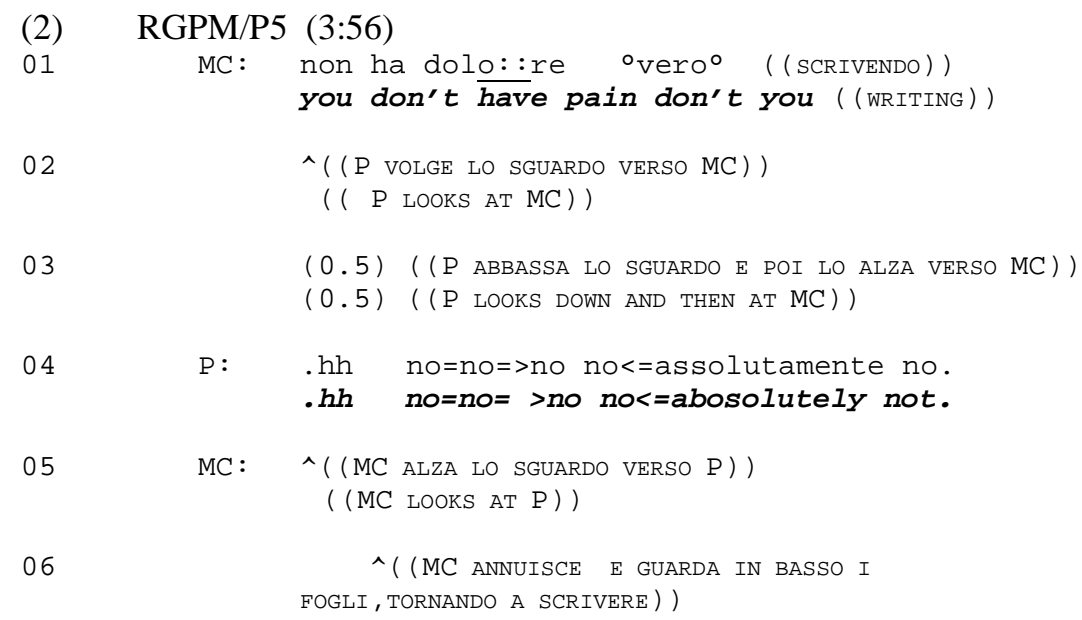




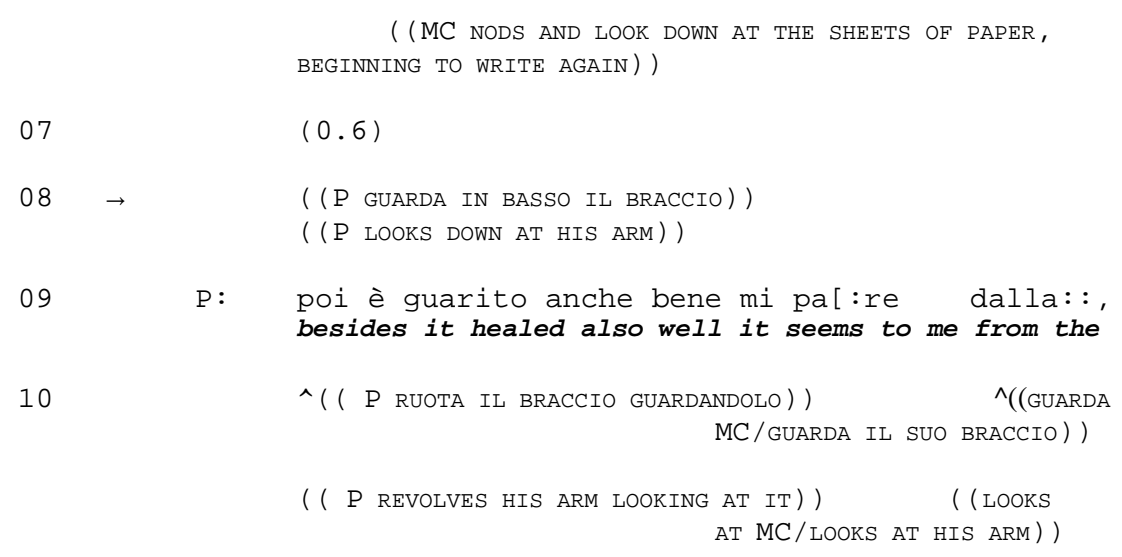

As previously highlighted, starting from line $8, \mathrm{P}$ produces an action that doctors did not solicited. The pause in line 7 is deployed post the ratification of the previous question-answer sequence completion, which is accomplished by means of MC's nodding (line 6), thus indicating that the answer has been acknowledged. Therefore, P's turn at line 9 is one of P's initiatives, although constructed as a continuation of prior turn (line 4), as we will show later. This action is an assessment on the state of the limb (how well it has recovered), which is being talked about and on which doctors have asked questions so far.

\section{a) Gaze}

The gaze management is the first component of the pattern. After the closure of the sequence, in line $8, \mathrm{P}$ addresses his gaze to his limb, which is also the object of MC's prior question (line 1). Notice that P has already looked at his arm some time before; that is, before answering to MC's question (line 3). By looking at the arm, $\mathrm{P}$ indicates that he is still concentrated on the limb and, by doing so, he signals the object of his action. Indeed, the talk which $P$ produces in line 9 is an assessment about his arm's recovery which is a topic not yet addressed by the doctors. ${ }^{3}$ The

\footnotetext{
${ }^{3}$ On this regard, it is worth recalling that during this phase of the visit doctors gather medical information on P's physical conditions and on the history of the amputation. Moreover, it is important to know that MC's questioning follows the list of questions printed on the form that he is filling in with P's answers. Therefore, MC's behaviour is strictly based on the written text, which doesn't seem to include any assessment on the recovery of the limb. This context makes more relevant P's initiative, in terms of independence and of mitigation of the conversational asymmetry.
} 
assessment is the result of a complex integration of talk with other resources, such as gaze and gestures. ${ }^{4}$ The fact that the assessment comes after P's gaze on his his limb, characterises it as the objective reporting of a state that is thus made accessible to/by the speaker at the precise moment when the assessment is made. ${ }^{5}$ Furthermore, considering that the assessment of the limb's recovery, whose observation $\mathrm{P}$ exhibits, is an activity that normally belongs to doctors, the fact that $\mathrm{P}$ produces it could be seen as a challenge to the doctors' authority. In this respect, therefore, the assessment argues for a reduction of the asymmetry, since P acts as an autonomous informant (Ten Have, 1991) and, moreover, he does it on the ground of an independent evaluation. ${ }^{6}$

b) Talk

In this section we analyse the way in which $\mathrm{P}$ constructs this action verbally. The first observation concerns the fact that P's assessment is in first position (Pomerantz, 1984). However, when looking at the verbal format and choices made by $\mathrm{P}$, the strength of this initiative (which is a first action) is mitigated by a series of linguistic devices. First, with the "poi" ("then" as turn initial) the turn is characterised as a continuation of the prior turn and, therefore, as an expansion of the answer. This continuation function is also achieved thanks to the conjunction "anche" ("also"), which re-enforces the turn character as a resumption or expansion of the topic previously dealt with. This characterisation of the turn as additional makes it weaker as autonomous initiative. A further feature, contributing to mitigation, is the "mi pare" ("it seems to me"). Besides adding to the mitigation of the statement," the expression "mi pare" solicits the

\footnotetext{
${ }^{4}$ A review of prior studies on assessments as a multimodal phenomenon, starting from the seminal works by Goodwin e Goodwin, is presented in Lindström and Mondada (2009). ${ }^{5}$ Speakers can also produce assessments about past events to which all participants have taken part or witnessed together, or on events which each participant has had access to at different times, or else on events that are accessible to the speaker only (not to the recipient). For a literature review on assessments, starting from Pomerantz' seminal works (1984), see again Lindström and Mondada (2009).

${ }^{6}$ Gill (1998) has studied patients' auto-diagnosis and 'non-expert' explanations of their own health conditions. She found that, when patients carry on these activities, they adopt particular types of caution and mitigation in presenting their explanations.

${ }^{7}$ Pomerantz defines statements prefaced by this type of expressions as 'weakly stated'. For a review of the linguistic forms that are used to mitigate assertions or assessments, see Brown and Levinson (1987). Caffi (2001) and, more recently, Gili Fivela and Bazzanella (2009) have studied the linguistic realization of mitigation -and of intensity, as the reciprocal phenomenon- in spoken Italian.
}

Formattato: Tipo di carattere: Corsivo

Formattato: Tipo di carattere: Corsivo 
recipient's confirmation. Finally, the last feature that contributes to mitigate the force of the assessment relates to the fact that the utterance is not complete; indeed, P leaves the utterance unfinished, by not articulating the last word. By leaving the last word unexpressed, $\mathrm{P}$ breaks the grammatical link between [preposition + noun]; a link that, in Italian, is very strong. This practice works to invite recipients to complete the utterance collaboratively and, consequently, to engage them into the assessment. In this way, $\mathrm{P}$ sets the conditions for the expression of agreement from the doctors.

\section{c) Gestures}

| As said before, in this multimodal pattern gestures accompany talk and gaze; thus we consider this aspect as the last one only for organisational reasons. The gesture we analyse here is the rotation of the forearm, which $\mathrm{P}$ makes when starting to speak at line 9. By making this arm rotation while fixing his gaze on it, $\mathrm{P}$ constructs the gesture as producing evidence for what he is saying: that is, that the limb has recovered. Thus, $P$ enacts the act of observing his arm carefully and thoroughly, displaying that his assessment is trustworthy. This enactment of the gesture is designed to show that the whole activity is actually grounded on criteria elaborated at the exact moment when the assessment is produced, and accessible both to the speaker and to his recipients, as well. The reference to an accessible and visible object -to the "here and now", which is achieved by means of "the gestures being made and observed by the speaker"-, has the function of providing grounds for the assertion that is being made and, furthermore, of inviting doctors to take part in the assessing activity. In this way, P creates the empirical and observational basis whereby an assessable object is made accessible to doctors too. P's gaze on MC at the end of his turn works as a further solicitation to answer.

We will now turn to a second example, in which the same pattern is produced in the course of another visit. In fragment 3, the doctor team meets a patient who had both hands injured in a working accident. The right hand is in worse conditions, having lost the thumb. The transcription starts after $\mathrm{P}$ has given his personal details and has informed the doctors about the dynamics of the accident. In line 1, the physician (MC) checks his comprehension of P's story about it. In this case, a hand surgeon (MB) is also part of the medical team; when the transcript starts, MB is busy reading the report of the complex surgery $\mathrm{P}$ had undergone in the hospital of the town where he lives.

Formattato: Tipo di carattere: Times New Roman, Corsivo

Formattato: Tipo di carattere: Corsivo 
(3)

RGPM/P3 (01. 08)

01 MC: quindi è finita la mano nel pisto:ne? so the hand was caught up in the cylinder DESTRA COME SE STESSE TAGLIANDO))

( (UNISCE LE MANI E POI MUOVE LA MOVESHIS RIGHT HAND AS HE WAS CUTTING))

$\mathrm{MC}:$

$\wedge($ (ANNUISCE RIPETUTAMENTE) )

( (NODS REPEATEDLY))

P: =caduto male, (.) poi è partito pistone fell badly then cylinder started

( (LA SPIEGAZIONE È ACCOMPAGNATA DA GESTI))

( (THE EXPLANATION IS ACCOMPANIED WITH GESTURES))

(0.6) / ( (MC CONTINUA AD ANNUIRE E ABBASSA LO SGUARDO SUL TAVOLO ))

$(0.6) /((M C$ KEEPS NODDING AND LOWERS HIS GAZE ON THE $D E S K))$

MC: ${ }^{\circ}$ ho capito ${ }^{\circ}$ / ( ( COMINCIA A SCRIVERE $\left.)\right)$

I understand /( (BEGINS TO WRITE) )

$(0.6) /(($ I MEDICI SONO IMPEGNATI CON I DOCUMENTI $))$ $(0.6) /(($ DOCTORS ARE BUSY WITH DOCUMENTS) )

( (DURANTE QUESTO PERIODO DI TEMPO, MB ALZA LO SGUARDO SULLA MANO DEL PAZIENTE PER UNA FRAZIONE DI SECONDO E POI TORNA A LEGGERE IL PROTOCOLLO DELL' OPERAZIONE CHIRURGICA))

( (MB RAISES HIS GAZE ON THE PATIENT'S HANDS FOR A FRACTION OF A SECOND AND THEN RETURNS TO READ PROTOCOLS ABOUT THE SURGERY))

\begin{tabular}{|c|c|c|}
\hline 08 & P : & $\begin{array}{l}(0.6) \text { tutt'e due le mano nella: }: \\
(0.6) \text { both hands in the }\end{array}$ \\
\hline 09 & & $\begin{aligned} & ((\mathrm{P} \text { GUARDA IN BASSO VERSO LE SUE MANI })) \\
& ((\mathrm{P} \text { LOWERS HIS GAZE ON HIS HANDS }))\end{aligned}$ \\
\hline & & $\begin{aligned} & \wedge \\
\text { PRIMA GUARDANDO VERSO } & \text { MC CHE SCRIVE E POI VERSO MB })) \\
( & (\mathrm{P} \text { TOUCHES THE FINGERS OF HIS LEFT }\end{aligned}$ \\
\hline & MB : & $\begin{array}{c}\hat{\wedge} \\
((\text { GUARDA P })) \\
((\text { LOOKS AT P }))\end{array}$ \\
\hline
\end{tabular}


(1.4) / ( (P RIPETE IL GESTO CON ENTRAMBE LE MANI VERSO MC CHE ORA LO STA GUARDANDO))

$(1.4) /((P$ REPEATS THE GESTURE WITH BOTH HANDS TOWARD MC WHO IS LOOKING AT HIM))

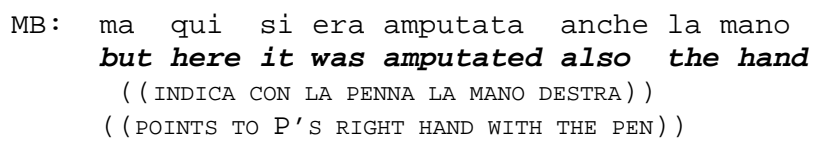

Similarly to what we described as happening in the previous fragment, P's action takes place after the conclusion of a question-answer sequence, whose closure is ratified by the doctor ("ho capito"/ "I understand", line 6). Formattato: Tipo di This sequence (composed of question-answer-receipt), is followed by a carattere: Corsivo pause, during which all doctors are engaged in different activities: either reading the medical files (MB) or filling-in the forms with information about P's health conditions and his medical history (MC). Probably reacting to the surgeon gazing at him (as reported in the gloss after line 7), $\mathrm{P}$ takes the initiative. In line 8 , while lowering his gaze on both hands resting on the table in front of him, $\mathrm{P}$ constructs his turn in which he corrects the presupposition of MC's question in line 1. P's turn in line 8 ("OI mean, ${ }^{\circ}(0.6)$ both hands in the: :,", highlights that both hands were injured, not only one as the question in line 1 seems to imply.

We will make here a brief digression in order to make some observations regarding the way in which P's action realised by means of the multimodal pattern, here arises in a rather different sequential environment from the one we observed in the previous episode. These circumstances, however, do not detract from our interpretation. As noted above, the lowering of P's gaze on his hands immediately follows the moment in which MB looks at P's hands (lines 7 and 8). Owing to this, it appears that P's gaze is the result of his aligning to MB's action, rather than being his own independent initiative; thus characterising P's action as different from the action produced by $\mathrm{P}$ in example 2, which has a more independent nature. However, the sequential position of P's initiative -that is, after MB has turned to look at P's hands- does not contradict the analysis we proposed about example 2 (in which this pattern is used by $\mathrm{P}$ to regain his speaking space to develop further the topic dealt with in the previous sequence). On the contrary, our interpretation ends up re-enforced. As a matter of fact, it is exactly because $\mathrm{P}$ produces his multimodal turn in response to MC's gaze on his hands that participants display to consider this practice -looking at the object (whether it is the doctor or the patient 
who mobilises the gaze) - as a way of re-addressing a topic that was just being discussed. Thus, both P and MB use the gaze to the same ends; that is, as a tool to announce and construct the re-topicalisation of the limb. It is at this point that $\mathrm{P}$ corrects the informative item implied in MC's question in line 1 , by pointing out that his both hands were involved in the amputation.

This episode is similar to previous example 2 also regarding the turn construction. Also in this case, in fact, $\mathrm{P}$ begins his turn with a conjunction ("cioè"/"that is") that refers to previous talk. Another feature which links P's turn in line 8 to the question in line 1 is the fact that P's turn has the same syntactical format of MC's question. The utterance in the doctor's question "quindi è finita la mano nel pistone?" "so the hand was caught up in the cylinder?" becomes "tutt'e due le mano nella" "both hands (were caught in) the" in P's turn. He, thus, constructs a repetition with some variations. The propositional content of MC's question is proposed in a more elliptical way in P's version, as highlighted below:

- the expression "tutt'e due le mano" / "both hands" substitutes "la mano"/ "the hand";

- the verb "finire" / "be caught in " is not explicitly formulated, but it is elliptically recalled by means of the preposition "nel" / "in the" (sing. masc.), here transformed into "nella" / "in the" (sing. fem.);

- P leaves unsaid where the hands were caught into; .

In conclusion, the prefacing conjunction " cioè" / "I mean" and the turn structure that reproduces the format of the doctor's question contribute to understanding P's turn as a repair of the presuppositions implied in MC's question in 1 . In addition, and again similarly to example 2 , here the turn is not complete and the last word produced by $\mathrm{P}$ is a preposition projecting the noun ("macchina", "sega", / "machine"," saw" etc.) that should complete the noun phrase, "tutt'e due le mano nella" / "both hands were caught in the ".

Finally, $\mathrm{P}$ produces the gesture of pointing to one hand with the other (lines $10 \mathrm{e} 12$ ), making a gestural reference which, as in example 2, has the function of specifying a part or an aspect of the limb the recipient is requested look at. The purpose of the gesture is to display and make

\footnotetext{
${ }^{8}$ It might be worth knowing that $\mathrm{P}$ is not a native speaker of Italian, although he can-speak Italian effectively and he is perfectly able to conduct the interaction with the doctors. he uses the singular form "mano" for "hand" (instead of "mani" for "hands"), but it is clear fthat he is referring to both hands, because he uses the numerical adjective "due" for "two".
} 
accessible to the expert-recipient the evidence of what $\mathrm{P}$ (the non-expert speaker) is asserting. At the same time, through the gesture, $\mathrm{P}$ solicits the doctors' involvement in the action that is being carried out, making their aligning relevant. Therefore, in this example, as well as in example 2, $\mathrm{P}$ takes his autonomous initiative by means of the same multimodal pattern, consisting in a combination of gaze, talk and gestures.

Our last example is illustrated in the following extract. The fragment below takes place during the physical examination of P's forearm. $\mathrm{P}$ has just performed some movements with both his forearms according to the doctors' instructions. When the fragment begins, doctors are assessing P's performance:

(4) RGPM/P5 (03.16)

\begin{tabular}{|c|c|c|c|}
\hline 01 & & MC : & $\begin{array}{l}\text { C'è la prono }{ }^{9}-\text { supina }\left[\mathrm{zio} \text { : ne }{ }^{10}: \text {, (.) conserva:ta }\right. \\
\text { there's the prono-supination maintained } \\
((\text { COMPIE GESTI ROTATORI CON LA MANO DESTRA)) ^((SPOSTA LO } \\
\text { SGUARDO DALL' AVAMBRACCIO DI P A MA)) } \\
((\text { MAKES ROTATING GESTURES WITH RIGHT HAND)) ^((SHIFTS } \\
\text { GAZE FROM P'S FOREARMS ON MA)) }\end{array}$ \\
\hline 02 & & MA: & $\begin{array}{l}{\left[\mathrm{sì:} c^{\prime} \text { è un } \downarrow \text { po'. }{ }^{\circ} \text { sì sì. }\right.} \\
\text { yes there is a little yes yes }\end{array}$ \\
\hline \multirow[t]{3}{*}{03} & $\rightarrow$ & P : & SGUARDO IN BASSO SULI' ARTO ) $) \wedge((\mathrm{P}$ VOLGE LO \\
\hline & & & （（P LOWERS \\
\hline & & & HIS GAZE TOWARDS HIS LIMB \\
\hline 04 & & MA : & $\begin{array}{r}\text { sì sì. }{ }^{\circ} \mathrm{C}^{\prime} \mathrm{è} \mathrm{un} \mathrm{po'.} \mathrm{uhuh,} \mathrm{va} \mathrm{bene,} \mathrm{gra}[\mathrm{zie} \\
\text { yes yes ther's a little uhuh that's fine thank you } \\
\wedge((\text { VOLGENDOSI VERSO } \mathrm{P}) \\
((\text { TURNING TO } \mathrm{P}))\end{array}$ \\
\hline 05 & $\rightarrow$ & P : & $\begin{array}{l}\text { ((P MANTIENE LO SGUARDO SULL' ARTO E LA POSTURA ASSUNTA } \\
\text { PER L' ESAME FISICO }) \text { ) } \\
((\text { P MAINTAINS HIS GAZE ON HIS LIMB AND THE POSTURE HE } \\
\text { ASSUMED DURING THE PHYSICAL EXAMINATION) ) }\end{array}$ \\
\hline 06 & & $\mathrm{P}:$ & $\begin{aligned} & \text { [c'è un= } \\
& \text { there is a }\end{aligned}$ \\
\hline 07 & & & $\begin{array}{l}\text { INDIETRO. MUOVE I MUSCOLI DELL'AVAMBRACCIO, FACENDO } \\
\text { MUOVERE LA PARTE SUPERIORE DELL'ARTO }))\end{array}$ \\
\hline
\end{tabular}

\footnotetext{
${ }^{9}$ Pronation (anatom.): Forearm rotation with the palm of the hand downward and/or backward.

${ }^{10}$ Supination (anatom.): Forearm rotation of the forearm with the palm of the hand upward or/and forward.
} 
BACK. MOVES HIS FOREARM'S MUSCLES MOVING THE UPPER PART OF HIS LIMB) )

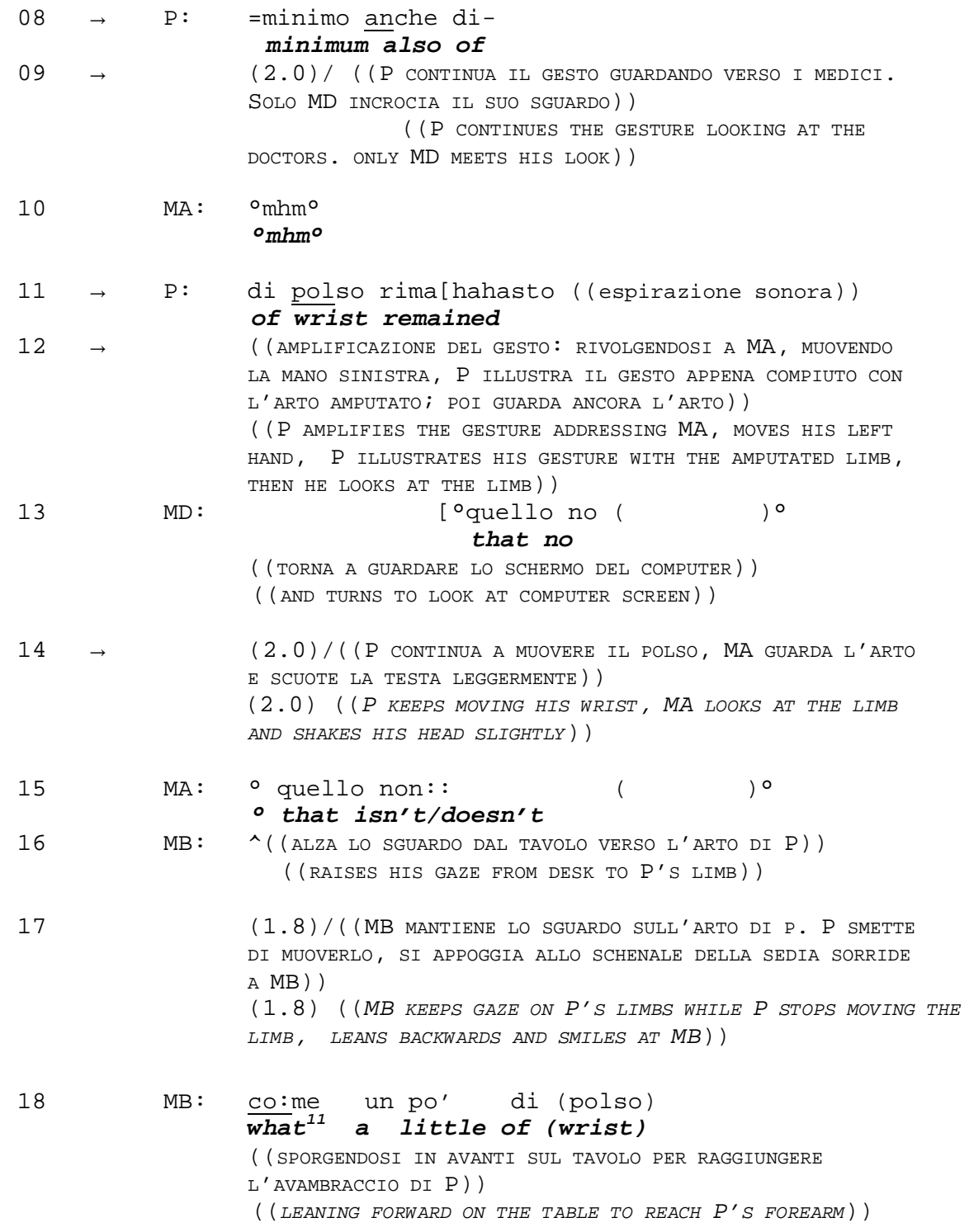

11 Here "what" means "what do you mean by....." 
Like in the previous examples, here also the patient takes the initiative after the prior sequence reaches its conclusion; in this case, the sequence is a series of assessments produced by the doctors (lines $1-4$ ). MC produces the first assessment (line 1), followed by MA's agreement (line 2). While the second assessment is produced, $\mathrm{P}$ fixes his gaze on his limb, which is the object of the ongoing examination (line 3). Subsequently, in line 4, MA repeats part of his own prior turn ("sì sì c'è un po" / "yes yes there is some"). After that, MA thanks P for the performance. In this way, MA ratifies the conclusion of the physical examination and of the diagnosis phase. In a similar way as the two previous examples, it is at this point that $P$ produces the multimodal pattern at issue.

First, although MA's thanks $P$, thus signalling the end of the examination phase (line 5), $P$ does not turn his gaze away from the limb, nor he releases the posture he adopted in order to undergo the physical exam. Instead, he remains in the same position as before, with both his elbows on the table and he keeps looking at his amputated forearm. As we showed in the previous examples, gaze fixing on the object of the talk just concluded is one of the three features of this phenomenon. By keeping his gaze on the limb, P displays to be oriented to the same topic as before. The gaze on the limb is accompanied by $\mathrm{P}$ 's verbal production (line 6): an assessment. It is worth considering that $\mathrm{P}$ does not explicitly verbalises the object of this evaluation (which, instead, is indicated through the gaze); this means that the gaze has a referential function in the overall practice here examined. The turn construction presents many similarities with the two previous fragments. In this case too, P's initiative is constructed with a turn that is designed as linked to prior talk, by means of the conjunction "anche" / "also"". This link with prior talk is further emphasised by the fact that here also, like in fragment 4 , the format of the turn repeats that of the doctors' prior turns in lines 1, 2 e 4: $\mathrm{P}$ uses the format "c'è X" / "there's $\mathrm{X}$ ". Again, like in the two previously examined examples, $\mathrm{P}$ introduces verbal elements and syntactical patterns designed to mitigate the force of his initiative and assessment. Regarding the mitigating aspect of the practice in the verbal production, two main observations are relevant here. First, notice the use of the expression "un minimo di" / "a minimum of" (line 8), which in itself is minimising the assertion. Second, $\mathrm{P}$ leaves this noun close incomplete, by not producing the expected noun after the preposition "di". Like in prior fragments, this practice invites collaborative completion and, thus, the participation of recipients in P's ongoing activity. Finally, also this assessment expressed by $\mathrm{P}$ is constructed as bearing on 
the objective datum that is made relevant by $\mathrm{P}$ 's gesture. The gesture that $\mathrm{P}$ produces in line 7 shows to his interlocutors what exactly he means when carattere: Corsivo he says that there seem to be some of the "polso" / "wrist" activity remained. In this way, $\mathrm{P}$ also makes this datum accessible to his interlocutors. Thus, the whole activity, whereby $\mathrm{P}$ makes the object of his assessment accessible to doctors, has a double function: that of of providing evidence for his statement and of eliciting the recipients' participation.

Concluding this examination of the pattern's construction, the features the three fragments have in common are :

- P's action takes place after the ratified conclusion of a prior question-answer sequence initiated by one of the doctors (ex. 3 and 4) or after a sequence of assessments produced by doctors about the physical examination (ex. 5);

- the gaze fixed on the limb introduces and accompanies P's talk, with the function of displaying that $\mathrm{P}$ keeps being oriented on the topic just discussed in prior talk;

- P makes a series of lexical and syntactical choices so as to design his initiative as an expansion of his own prior turn or as part of the prior sequence; furthermore, the turn presents some lexical and syntactical components that mitigate the force of the action thus enacted (including the practice whereby the utterance is left unfinished);

- P performs gestures to show which parts or aspects of his limb are the object of his attention and provide evidence for his assessments and assertions, making them accessible to doctors as well.

\section{Conclusions}

Formattato: Tipo di carattere: Times New

Our analysis has shown that patients use this multimodal pattern to escape Roman, Grassetto from the limited discursive role of mere "respondents" and to produce autonomous initiatives, often constructed as expansions of prior talk. These initiatives take place when the doctors show that the sequence they initiated-a question-answer sequence or a series of assessments, or even the closure of a whole phase of the visit, such as, for example, the examination of P's limb in fragment 4- has reached conclusion. In the conversational space, which patients gain by means of this specific pattern, they enact different types of actions; these can be, for example, providing 
unrequested information during the phase of the history-taking (ex. 2 ), correcting the implicit assumptions of the doctor's question (ex. 3), and formulating autonomous assessments (ex. 4). In all the episodes we examined, the multimodal pattern constructs the action as related to aspect regarding the limb under examination, to which patients refer to by look at it. This way of gazing and moving the limb, while they talk about it, has the function of showing to doctors on which grounds they base their action. . Thus, they use their limb as the evidence for what they are saying, displaying to have a certain authority. By looking at their own limb and by moving it, patients become competent speakers because they have -and display to have- direct experience of the amputated limb and of the problems connected to it, and which are the medical concern in these clinical encounters. By constructing their interactional initiatives as grounded in the empirical competence of their own body and of their limb, they manage to justify and legitimise them as acceptable actions in this setting.

The evidence that patients have skills in securing themselves additional speaking spaces, as we have demonstrated here, confirms the recent change in the view of patients' discursive roles and ways of participating to clinical encounters, partially freeing them from the passivity with which prior and more traditional studies characterised them. ${ }^{12}$ On the other hand, exactly because they build their authority for these conversational contributions as dependent on the doctors' acknowledgment of the empirical and objective grounds (the exposition of the limb to the doctors gaze and attention through this practice), patients actually downgrade their actions thus constructed. In conclusion, patients' conducts we described here have a double contrasting function. The first function is to reduce the interactional asymmetry that characterises the interaction in these types of settings, because patients succeed in taking distinctive initiating actions. The second contrasting function (in line with the study by Teas Gill, 1998), is to show that they are still orienting to the asymmetry that is proper of doctor-patient interaction, and which they contrast. Patients achieve this result by mitigating the action in different ways: first, by making lexical and syntactical choices that downgrade their assertions and, second, by constructing their initiatives as exclusively related to the empirical and experiential domain of their body and symptoms (non-expert domain).

\footnotetext{
${ }^{12}$ On this regard, see Costello and Roberts (2001), in which they show that also in the prescription phase of the visit, patients may take an active role, socially negotiated and collaborative.
} 


\section{References}

Atkinson J. M. and Heritage J., eds. (1984). Structures of Social Actions: Studies in Conversation Analysis. Cambridge: Cambridge University Press.

Boyd E. and Heritage J. (2006). Taking the Patient's Medical History: Questioning During Comprehensive History Taking'. In: Heritage J. and Maynard D. (eds), Communication in Medical Care: Interactions between Primary Care Physicians and Patients. Cambridge: Cambridge University Press.

Brown P. and Levinson S. (1987). Politeness: Some Universals in Language Usage. Cambridge: Cambridge University Press

Caffi C. (2001). La mitigazione. Un approccio pragmatico alla comunicazione nei contesti terapeutici. Münster: LIT Verlag.

Costello B. A. and Roberts F. (2001). Medical Recommendations as Joint Social Practice. Health Communication 13(3): 241-260.

Drew P. and Heritage J. eds. (1992) Talk at Work: Interaction in Institutional settings (Studies in Interactional Linguistics). Cambridge: Cambridge University Press.

Gili Fivela B. e Bazzanella C. a cura di (2009). Fenomeni di intensità nell'italiano parlato. Firenze: Franco Cesati Editore.

Gill V. (1998). Doing attributions in medical interaction: Patients' explanations for illness and doctors' responses. Social Psychology Quarterly 61 (4): 342.

Gill V. and Maynard D. (2006). Patients' Explanations for Health problems and physicians' Responsiveness in the Medical Interview. In: Heritage J. and Maynard D. (eds.). Communication in Medical Care: Interaction between Primary Care Physicians and Patients (Studies in Interactional Sociolinguistics). Cambridge: Cambridge University Press.

Lindström A. and Mondada L. eds. (2009). Assessments in Social Interaction: Introduction to the Special Issue. In: Research on Language and Social Interaction. 42(4): 299-308.

Pomerantz A. (1984). Agreeing and disagreeing with assessments: some features of preferred/dispreferred turn shapes. In: Atkinson J. M. and Heritage J., eds. Structures of Social Actions: Studies in Conversation Analysis. Cambridge: Cambridge University Press.

Robinson J. D. (2001) Asymmetry in action: Sequential resources in the negotiation of a prescription request. Text, 21(1/2): 19-54.

ten Have, P. (1991). Talk and institution: A reconsideration of the "asymmetry" of
Formattato: Tipo di carattere: Times New Roman, Grassetto 
doctor-patient interaction. In: Boden D. and D. H. Zimmerman D. H. (eds.)

Talk and Social Structure: Studies in

Ethnomethodology and Conversation Analysis. Los Angeles,

California: University of California Press. 